\title{
Developing good research habits
}

\section{Encourage students to create a working bibliography online}

\author{
by Kristin Miller
}

$\mathbf{R}$

emember Advanced Composition? Remember your numbered note cards with meticulously written quotes and paraphrases taken from library books and journal articles?

With the ease of access to information online, you don't see many college students traveling with 3 x 5 card boxes anymore. More often students are carrying multiple printouts from full-text journals or Web pages. The convenience of printing information from online sources is not worth arguing about-students want full-text. But where is the methodology for organizing the bits and pieces of information students pull from each source and how do they incorporate their own icleas and arguments in a research paper? Where is the research and writing process?

The absence of the $3 \times 5$ card box as an organizational tool for research has led to three epiclemic problems in the college online research environment: the printing epidemic; the disconnected research paper problem; and the plagiarism epidemic. A simple solution to these problems can be found on most campuses by incorporating word processing into the research process.

\section{Collecting printouts}

The largest growth area in the collection at the Todd Wehr Memorial Library at Carroll College has been in access to online full-text resources. As laser printing has become widely and freely available and the processing speed of our computers has increased, students can find and print information quickly. In this era, finding and printing information quickly seems like a fine objective.

Observing students with stacks and stacks of articles they had printed, I was surprised when one such student asked for help finding more information. I asked him what sources he had found already that were useful. The reply was simply that he hadn't really used the printed information, or even read it thoroughly, but that there might be a need for these printouts at some point.

The possible future need this student identified is often coupled with a fear that good information may never be found again. It becomes clear that students are not printing because what they have found will be useful in their research. In fact, printing a 25-page article does not necessarily mean the student will even read the article.

\section{Alternatives to printing articles}

Part of this problem can be solved by helping students become more comfortable with online search techniques. The basics of online searching will help them find the information they want without just stumbling over it.

Another solution to this problem is encouraging students to store the information they think will be valuable in a working bibliography.

On our campus, students have access to the library catalog and the online indexes from any networked computer. The majority 
of these computers have standard word processing applications like MS Word, WordPerfect, Word Pad, or Note Pad on them. With word processing so readily available, all students need to do is open a new file and cut and paste their citations and abstracts into a Word document. Most of these computers are also hardy enough to allow the user to keep more than one window open at one time and toggle back and forth quickly without waiting for each window to load.

Although the format of the clipped text may not align perfectly, once it is pasted it can be edited quickly. Popular indexes, such as "IAC," "EBSCO" and "FirstSearch," generally give three options for retrieving citations, abstracts, and full-text: print, e-mail, and save. The print option simply reformats the citation, abstract, or full-text so that it can be printed easily from the browser's print option. Once the screen is reformatted, it can be cut and pasted into a Word document.

E-mailing a document is an excellent option for students who are not prepared to save their citations on disks. Again, once these e-mailed citations are delivered, the student has the option of cutting and pasting them into a working bibliography. The e-mail option is often desirable because the student will not run the risk of losing data that is not translated between the library's word processing and the word processing on the student's personal computer. This is also important because the library relies on a Windows Operating System and students may use the Mac Operating System for their personal computers. Many faculty also use Macs in their offices. Using e-mail to collect citations allows the researcher to reformat them into a working bibliography on the computer and operating system that will be used to do the majority of the word processing.

The final option, saving a marked list of citations, is an excellent idea, but the lack of assurance that the disk will be readable from one computer to the next often stops people from saving directly to a floppy. On our campus, students and faculty also have the option of saving information directly to a folder on their Windows NT user profile.

\section{New techniques for synthesizing information}

There are rumblings from our teaching fac- ulty about the quality of student research papers. We have no doubt that students are finding information, because we have the printing epidemic to prove that they are using library resources. So where is the disconnect between finding information and actually writing a good paper?

Perhaps it is in the $3 \times 5$ card box that is no longer used. The $3 \times 5$ card box was the place where students recorded what they had learned from each information source. Each card represented a specific thought, fact, or new idea the student had gleaned from a book or a journal. You rarely see students "taking note" of what they read on a Web site. Students are more likely to print or photocopy the information they need, and in the best-case scenario, they will annotate or highlight the text.

Annotating and highlighting may be proof that the student has actually read the information; and for lengthy articles, reading from printed copy is more comfortable than reading from the screen. But by reading, annotating, and adding notes to a working bibliography, the student can begin to create an organized record of his or her thoughts on each source. In the age of the $3 \times 5$ card, after writing notes and quotations on each card, you could then arrange the cards in the order they would appear in the paper. So if you were writing from an outline, you could find all the cards that supported your statements and lay them out in the order you would write about them.

You could see which were your own ideas and conclusions and which were coming directly from your research sources. You might also be able to pick out parts of the paper that were obviously weaker than others and needed to be developed.

The same basic method of integrating the writing and research processes is still possible in the online environment. After cutting and pasting their citations into a word processing file, students can number and arrange the sources in a way that lets them keep track of their sources and their notes. The first quote from the first source might be numbered 1a. and so on.

If students can annotate on the printed copy of an article, they could also enter their notes into the working bibliography and begin collecting the information they are going 
to write about. This short process takes the student one step closer to integrating the various sources they've read. If this working bibliography were paired up with a statement outline, the student can again cut and paste the supporting notes or quotations into the outline and begin drafting.

\section{The plagiarism epidemic}

The online research environment seems to have opened the door to a new wave of plagiarism problems. A larger problem is that often students do not know they are plagiarizing when they simply restate something they've read without providing the source of the information.

Making students aware of plagiarism and how to avoid it is an important part of teaching them the ethics of research. One way of doing this might be to require students to turn in a working bibliography in which they list their sources immediately followed by the notes, quotations, or questions. Students might also be encouraged to think of this part of the process as writing down what they have learned from each source. Anytime they have learned something new, they should give proper credit to that source in the final paper. This gives students the opportunity to separate their own arguments and conclusions from the information gleaned through research. ${ }^{1}$

Developing the research habit of writing from a working bibliography will teach students to use technology to do better research and writing. In this case, technology is actually used to engage the critical thinking skills students need to be effective writers and researchers.

\section{Note}

1. Basic guidelines for creating a working bibliography can be found in the $M L A$ Handbook for Writers of Research Papers, $5^{\text {th }}$ ed. (New York: Modern Language Association of America, 1999)
("My year..." cont. from page 417)

This was an irreplaceable opportunity to step outside the library proper and consider its role and rank within the university's greater structure, as well as to meet and learn from experienced colleagues who were not librarians.

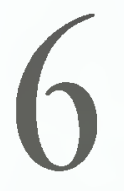

The playing field becomes the university, not the library. One decision you have to make about whether you aspire to being a "permanent" library director is whether you want to swim in this much, much larger pond. If you enjoy the challenges and rewards of librarianship per se, then the director's role may not be one you should seek. Having been associate director to two directors and having served as interim director, this desire to operate on a broader field seems to me the singular difference between being an associate director and being the director.

Skill, knowledge, experience and preparation are important prerequisites, but the true mark of a director is that she or he is not happiest in any other role. It sounds almost too simple, but I'd bet that most library directors would say that directorship has been their career goal right from library school.
The "vision thing" is not just hype. It is real and immutable to the person who is only fulfilled when creating that which doesn't exist, rather than when managing that which already exists.

I recommend the interim experience without reservation to all who would aspire. The opportunity comes along rarely in one's career and it should not be missed. For me, it was a learning experience for which there can be no substitute, an irreplaceable course in self-discovery and a chance to measure myself against the larger yardstick.

\section{Note}

1. East Carolina University is a constituent institution of the University of North Carolina system and serves an enrollment of 17,800 students. Academic Library Services consists of the main library, Joyner Library, and a branch Music Library. During this period, the collection size was $1,030,000$ volumes $/ 5,500$ periodical subscriptions and the library employed 27 faculty members and 76 staff members. The library is managed collegially by the director and a tenured faculty body according to the Faculty Manual and the library's Code of Operations. 